\title{
The Tyramine Pressor Test May Have Limited Sensitivity, Especially in the Presence of Dual Serotonin/Norepinephrine Uptake Inhibition ${ }^{\text {in }}$
}

Turcotte and colleagues (2001) recently reported that duloxetine at oral doses up to $60 \mathrm{mg} /$ day failed to blunt the pressor response to intravenous tyramine. However, recent data suggests that the tyramine pressor test results may be significantly confounded by several not yet understood factors. Prominent among these factors is the influence of concomitant serotonergic drug action. For example, venlafaxine, a serotonin and norepinephrine reuptake inhibitor (SNRI), also has a reduced effect on the tyramine challenge at the same doses that indicate physiologic norepinephrine activity (i.e., significant increase of blood pressure and heart rate) (Harvey et al. 2000). Additional confounding influences on the tyramine challenge include the duration of treatment prior to challenge and potential physiologic differences between normal and depressed subjects (Debonnel, et al. 1998; Harvey, et al. 2000).

Duloxetine demonstrates potent inhibition of both serotonin and norepinephrine uptake, with similar affinities, in several preparations including cloned human receptors (Bymaster et al. 2001). Duloxetine also produces simultaneous increases in extracellular serotonin and norepinephrine in rat hypothalamus and frontal cortex (Wong et al. 2000). Duloxetine at 80-120 $\mathrm{mg} /$ day in humans produces a reduction of urinary norepinephrine and its metabolites similar in magnitude to desipramine $100 \mathrm{mg}$ (Chalon et al. 2000). At

Refers to PII S0893-133X(00)00220-7 these doses, duloxetine also produces hemodynamic effects consistent with norepinephrine reuptake inhibition (Demitrack 2001; Goldstein et al. 2001; Turcotte et al. 2001). Finally, at doses of 40-120 mg/day, duloxetine produces a pattern of other clinical effects (e.g., dry mouth, sweating) consistent with enhancement of noradrenergic tone (Goldstein et al. 2001). The preponderance of evidence (receptor binding affinities, microdialysis, in vivo metabolite turnover, vital sign changes, and clinical effect data) clearly indicates that duloxetine produces norepinephrine uptake inhibition.

This evidence indicates that the tyramine pressor test may be inadequate to assess norepinephrine reuptake inhibition, especially in the presence of concomitant serotonin reuptake inhibition. In addition, the preponderance of evidence indicates that duloxetine has a pharmacological profile of potent and relatively balanced serotonin and norepinephrine reuptake inhibition.

$$
\begin{array}{r}
\text { Stephane Chalon, M.D., Ph.D., } \\
\text { Peter R. Bieck, M.D., } \\
\text { David J. Goldstein, M.D., Ph.D., } \\
\text { Michael J. Detke, M.D., Ph.D., } \\
\text { Franklin P. Bymaster, R.Ph., } \\
\text { William Z. Potter, M.D., Ph.D., } \\
\text { Mark A. Demitrack, M.D } \\
\text { Eli Lilly and Company, } \\
\text { Indianapolis, IN }
\end{array}
$$

\section{REFERENCES}

Address correspondence to: Dr. Michael J. Detke, Lilly Research Laboratories, Lilly Corporate Center, Indianapolis, IN 46285, Tel.: (317) 277-6420, Fax: (317) 276-6026.
Bymaster FP, Dreshfield-Ahmad LJ, Threlkeld PG, Shaw JL, Thompson L, Nelson DL, Hemrick-Luecke SK, Wong DT (2001): Comparative affinity of duloxetine and ven- 
lafaxine for serotonin and norepinephrine transporters in vitro and in vivo, human serotonin receptor subtypes and other neuronal receptors. Neuropsychopharmacology 25:871-880

Chalon S, Granier L-A, Vandenhende F (2000): Duloxetine clinical evidence of sertoninergic and noradrenergic reuptake blockade. Presented at the American College of Neuropsychopharmacology; December; San Juan, PR.

Debonnel G, Blier P, St-Andre E, Hebert C, de Montigny C (1998): Comparison of the effect of low and high doses of venlafaxine on serotonin and norepinephrine in reuptake processes in patients with major depression and health volunteers. Int J Neuropsychopharmacol 1(suppl 1):17

Demitrack MA. (2001): Is there room to improve monoamine-based therapies? Presented at the Annual Meeting of the American Psychiatric Association (APA): May 2001; New Orleans, LA.
Goldstein DJ, Mallinckrodt C, Lu Y, et al. (2001): Efficacy and safety of duloxetine in the treatment of major depression. Presented at the Annual Meeting of the American Psychiatric Association (APA): May 2001; New Orleans, LA.

Harvey AT, Rudolph RL, Preskorn SH (2000): Evidence of the dual mechanisms of action of venlafaxine. Arch Gen Psychiatry 57:503-509

Turcotte JE, Debonnel G, de Montigny C, Hébert C, Blier P (2001): Assessment of the serotonin and norepinephrine reuptake blocking properties of duloxetine in healthy subjects. Neuropsychopharmacology 24:511-521

Wong DT, Bymaster FP, Dreshfield-Ahmad L. (2000): Effectiveness of duloxetine and venafaxine in producing increases in extracellular levels of serotonin and norepinephrine in brain. Presented at the American College of Neuropsychopharmacology; December, 2000; San Juan, PR. 